\title{
De fantasmas indios y otros olvidados. El cine de terror como vindicación de minorías sociales y la extinción natural*
}

\author{
Antonio Míguez Santa Cruz
}

Recibido: 4 de marzo de 2017 - Aprobado: 7 de abril de 2017

\section{Resumen}

Todas las civilizaciones de la historia han creído o creen en fantasmas. Pero más allá del hecho semirreligioso o trascendental, la figura del retornado esconde multitud de lecturas sociales, históricas o antropológicas dignas de mención. El caso que deseamos poner de relieve es la enorme cantidad de espectros que en vida fueron parias, marginados o pertenecientes a alguna minoría de una sociedad dada. Un caso muy evidente ya estudiado es el de las mujeres en Japón, aunque también se puede aplicar en la cultura estadounidense a través de los espíritus de indios o negros.

El cine, como plataforma artística y de entretenimiento más popular, ha explotado, prácticamente desde sus inicios, el género del terror, por lo que nos parece interesante usar este medio para realizar un repaso por aquellos filmes donde aparecen espectros de nativos americanos o esclavos negros. Con ello, pretendemos demostrar que nos hallamos ante la contrarréplica narrativa o ficcional a dos traumas ahogados por el conjunto de la sociedad de EE. UU.: por una parte, el supremacismo, tan tristemente actual en los tiempos que corren, $y$ por la otra, la sempiterna dicotomía entre progreso y ecologismo.

Palabras clave: cine; genocidio; indios; venganza; espectros; ecologismo

Artículo de reflexión. Mi tesis doctoral afirma que la feminización del fantasma japonés se debe, a grandes rasgos, al sistemático maltrato dispensado a ese colectivo a lo largo de la historia de aquel país. Con el objetivo de hacer notar que la misma teoría puede aplicarse en otros ámbitos, culturas y geografías, se ha escrito este texto, demostrando así la relevancia antropológica, literaria y folclórica de una de las figuras más utilizadas en la narrativa universal: el fantasma. DOI: http://dx.doi.org/10.15332/s0120-8454.2017.0091.06

** Doctor en Historia del Arte, especialidad Cine. Universidad de Córdoba. Correo electrónico: 142misaa@gmail.com. Músico Ziryab n 9, 5 1. Córdoba (España) C.P. 14005. ORCID: http://orcid.org/0000-0001-7610-5616 


\title{
Of Indian ghosts and other oblivions. The cinema of terror as a vindication of social minorities and the natural extinction*
}

\author{
Antonio Míguez Santa Cruz
}

\section{A bstract}

Since the dawn of time, all civilizations throughout history have created or believe in ghosts; But beyond half-religious or transcendental facts, the figure of the returned entity hides a multitude of social, historical or anthropological readings that worth to be mentioned. The case we would like to highlight is the enormous amount of outcast or marginalized specters when they were alive belonging to some minority of a given society. A widely studied case is that one of women in Japanese culture, although it can also be applied to North American culture through the presence of the spirits of Indians or black people.

From the beginning, Cinema, as the most popular artistic movement or platform for entertainment, has exploited the horror genre, that is why it seem interesting for us to use this medium for doing a review of those films where native Americans or black slaves appear. Thus, we try to demonstrate that we are facing the narrative or fictional counter-reply to two traumas still present in the US society: on one side, the supremacy, so sadly experienced in our time, and on the other, the enduring dichotomy between progress and ecologism.

Keywords: cinema; genocide; american natives; revenge; ghosts; environmentalism

Reflection article. My doctoral thesis affirms that the feminization of the Japanese ghost is largely due to the systematic mistreatment given to this group throughout the history of that country. With the purpose of noting that the same theory can be applied in other fields, cultures and geographies, this paper has been written, thus demonstrating the anthropological, literary and folkloric relevance of one of the most used figures in the universal narrative: the ghost. DOI: http:// dx.doi.org/10.15332/s0120-8454.2017.0091.06

** Doctor of History of Art, specialty Film. University of Cordoba. Email: 142misaa@gmail.com. Musician Ziryab n $9,5^{\circ} 1$. Córdoba (Spain) C.P. 14005. ORCID: http://orcid.org/0000-0001-7610-5616 


\title{
Fantômes indiens et autres oubliés. Films d'horreur comme défense des minorités sociales et de l'extinction naturelle*
}

\author{
Antonio Míguez Santa Cruz ${ }^{* *}$
}

\section{Résumé}

Toutes les civilisations de l'histoire ont cru ou croient aux fantômes. Mais au-delà du fait semi-religieux ou transcendantal, l'image du revenant câche une multitude de lectures sociales, historiques ou anthropologiques dignes de mentionner. Le cas que nous voulons mettre en évidence est le grand nombre de spectres qui en vie étaient des parias, marginalisés ou appartennant à une minorité d'une société donnée. Un cas très évident déjà étudié est celui des femmes au Japon, mais il peut également être appliqué dans la culture américaine à travers des esprits des Indiens ou des Noirs.

Le cinéma, en tant que plate-forme artistique et de divertissement la plus populaire, a exploité presque depuis sa création, le thème de l'horreur, c'est pourquoi il nous paraît intéressant d'utiliser ce moyen pour procéder à une révision de ces films où apparaissent des spectres $\mathrm{d}$ 'amérindiens ou d'esclaves noirs. À travers cela, nous avons l'intention de démontrer que l'on se trouve face à la contreréplique narrative ou de fiction de deux traumatismes noyés para l'ensemble de la société américaine : d'une part, la suprématie si tristement d'actualité, et d'autre part, l'éternelle dichotomie entre le progrès et l'environnementalisme.

Mots clés: cinéma; génocide; indiens; vengance; spectres; environnementalisme

Article de réflexion. Ma thèse de doctorat affirme que la féminisation du fantôme japonais se doit, en gros, à l'abus systématique infligé à ce groupe tout au long de l'histoire de ce pays. Ce texte à été écrit dans le but de montrer que cette même théorie peut être appliquée dans d'autres domaines, cultures et géographiques, démontrant ainsi l'importance anthropologique, littéraire et folklorique de l'une des figures les plus couramment utilisées dans le récit universel: le fantôme. DOI: http://dx.doi.org/10.15332/s0120-8454.2017.0091.06

** Docteur en Histoire de l'Art, spécialité Cinéma. Université de Cordoue. Email: 142misaa@gmail.com. Musique Ziryab $n^{\circ} 9,5^{\circ} 1$. Cordoue (Espagne) C.P. 14005. ORCID: http://orcid.org/0000-0001-7610-5616 


\section{Introducción}

Con el estreno de The Ring (Hideo Nakata, 1998) el cine japonés de fantasmas comenzó a popularizarse a nivel global en una cadencia de películas deudoras que se prolongó hasta la segunda mitad de la década siguiente. La llamada J- Horror wave alcanzó un éxito sin precedentes por varias razones, aunque quizá la más destacada respondiese a las novedades aportadas en los usos del terror, con la importancia concedida al cabello como elemento perturbador, o la sugerente atmósfera que impregnaba aquellas cintas. Sin embargo, lejos de ser una moda coyuntural, ese fenómeno hundía sus raíces en el mundo de las mentalidades japonés, aparte de presentar algunos puntos de interés que merecían ser resueltos. El más importante, ¿por qué los fantasmas japoneses son mujeres en su mayoría?

Pensamos que la obvia feminización del espectro nipón se halla estrechamente relacionada con la coyuntura de desventaja que ellas han padecido en una sociedad militarizada en extremo y, por tanto, del todo masculina. Ese menoscabo social terminó por repercutir en la forma en que los japoneses imaginaron sus espectros, tal vez en una muestra inconsciente de miedo o remordiendo, entre otras emociones de reacción, ya fueren conscientes o no. El fenómeno alcanza el colmo del paroxismo con Sadako y todo el J-horror de aquella época, en el que decenas de espíritus buscaban compensar tras su muerte los horrores que, por el simple hecho de ser mujeres, habían sufrido en vida (Míguez, 2016, p. 173).

Pero la figura del fantasma como una alusión al sufrimiento del maltratado y como venganza figurada del outsider no solo es patrimonio de Japón y sus femíneos espectros. Al fin y al cabo, cualquier sociedad de la historia ha tenido sus propios parias y si los japoneses se han cebado con sus mujeres, los estadounidenses lo han hecho a su vez con los indios o los negros (Leyra, 1998, p. 60), así como los europeos focalizaron sus iras en dirección a los judíos o los gitanos. Es cierto que la producción fílmica de este género del terror es desigual según el caso, pero un seguimiento por ella nos ayudará a apuntalar nuestra teoría sobre la acción afirmativa post mortem en ciertos cauces de la industria cinematográfica.

\section{Brujos, animales y terrenos sagrados}

Antes de los años setenta, cuando la deliciosa ingenuidad de Roger Corman y la Hammer era lo predominante en un terror cinematográfico aún por asentar, la violencia y el odio sufridos por los indios ya hacía tiempo que se mostraba en los western sin dobleces, en un proceso a medio camino entre la naturalización y la censura de un hecho histórico consumado. Ahí están Centauros del desierto (The Searchers, 1956), Pequeño gran hombre (Little big man, 1970) o Un hombre llamado caballo (A man called horse, 1970) como ejemplos del sentimiento de culpa asentado en el inconsciente colectivo de una nación que el cine se encargó de reflejar. De cualquier modo, este reconcomio no es uniforme y si 
bien encontramos films como los anteriores, donde directamente se ejemplifica el genocidio, hay otros que tratan la cuestión desde una perspectiva más insinuante, sugestiva y simbólica. Así, el recurso del espíritu de un piel roja que vuelve buscando venganza es un método indirecto para reflejar un complejo nacional tan consciente de sí mismo como en cualquier otra película moralista de indios y vaqueros (Bosch, 1986, p.77).

Hablamos de un tópico, por cierto, mucho más precoz de lo que podríamos imaginar, pues Henry MacRae llevó al cine mudo The werewolf (1913), cortometraje donde una bruja india hechizaba a su hija con el fin de convertirla en lobo y así obtener la venganza sobre los colonos que asesinaron a su marido ${ }^{1}$. Desgraciadamente, el rollo de la película ha desaparecido ${ }^{2}$, pero hay consenso en afirmar que nos hallamos ante la primera muestra de licantropía en la historia del celuloide. Pese a ello, no conviene olvidar, al hilo de nuestro estudio, que tengamos una bruja y una mujer lobo como vertebradoras de la venganza. Aquí adquiere vital importancia la estrecha relación mística entre el fantasma indígena y lo animalístico, al punto víctima tan primordial de la conquista del Oeste como los mismos nativos que fueron masacrados. Por ello mismo, en este tipo de relatos estarán muy presentes el ecologismo y el folclore primitivista como elementos contrapuestos al avance capitalista y tecnológico ${ }^{3}$.

Haría falta un salto de más de medio siglo para llegar a la siguiente muestra de resarcimiento étnico con La venganza de Tartu (Death curse of Tartu, 1966), film de serie B poco atractivo y muy alejado de la genialidad demostrada por Jacques Tourneur en títulos de presupuesto similar como La mujer pantera o Robert Wise en El ladrón de cadáveres. La historia de nuestro film se desarrolla pesadamente mediante actuaciones de actores amateurs en medio de un seductor paraje de fondo, las llamadas everglades, zona pantanosa del sur de Florida y en su momento refugio de muchos indígenas ante la llegada de los colonizadores a mediados del s. XVI. Parece que este fue el punto de partida utilizado por el director William Grefe, ya que el chamán indio antagonista de la producción fue asesinado en ese siglo por invasores españoles. Por consiguiente, Tartu, que así se llamaba el damnificado, juró vengarse de cualquier piel blanca que execrase su tumba y enturbiase su sueño eterno. Cuatrocientos años después, un grupo de jóvenes biólogos llega a la zona para estudiarla, momento aprovechado por el fantasma para desperezarse y acabar con sus enemigos. Pese a la mediocridad general del trabajo, se pueden destacar virtudes, como la creíble atmósfera conseguida o el hecho de constituir un claro antecedente del popular género slasher ${ }^{4}$, inaugurado por John Carpenter mediante su célebre La noche de Halloween más de dos décadas después (Téllez, 2007, p. 581).

\footnotetext{
http://www.silentera.com/PSFL/data/W/Werewolf1913.html. Consultado (23/062016).

En un incendio producido en almacenes de la Hammer en 1924.

Exactamente igual que ocurre con el ecologismo visto en Ghibli.

4 Subgénero del terror cinematográfico donde un psicópata elimina a multitud de víctimas normalmente en edad adolescente. Si bien lo común es que este tipo de películas huya del fantástico o la naturaleza sobrenatural, podemos hallar
} muestras como La venganza de Tartu, Pesadilla en Elm Street o incluso Viernes 13. 
Imagen 1. Observando esta imagen muy cercana al pulp el lector podrá imaginarse fácilmente el tono del filme.

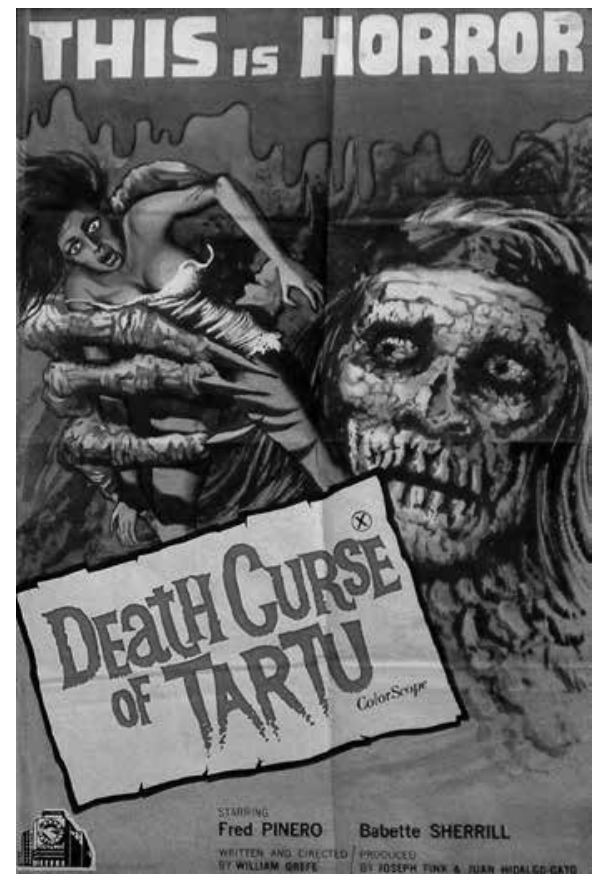

Fuente: Cartel estadounidense de La venganza de Tartu.

En el mismo año llegaría La amante del diablo (The Devil's Mistress, 1966), película que combinaría elementos de las dos anteriores, aunque imprimiendo un leve salto de calidad. Ambientada en 1880, relata cómo un grupo de forajidos asesina a un granjero y viola a su esposa india. Poco después, los integrantes de la banda comienzan a morir inexplicablemente gracias al influjo de la mujer, en lo que sería un recurso similar al usado por Kaneto Shindō en El gato negro (Yabu no naka no kuroneko, 1968). También de pocos recursos, la producción cuenta, sin embargo, con mayor sobriedad escénica, apuntalada por unas actuaciones creíbles y que destacan ante la ausencia de música y los yermos paisajes del sur de EE. UU. Es notable la escena en que Liah, la joven indígena, arrebata la vida a uno de los bandidos por medio de un beso, recordando a diversas criaturas del folclore japonés como la hone onna, o la sirena y el súcubo en la mitografía europea (Pedraza, 1996, p.157).

Diez años después, nos encontramos con un título interesante llamado La sombra del águila (The Shadow of the Hawk, 1976), cuyo valor reside en que el objeto de la venganza no es la raza blanca en sí misma, sino los descendientes de indios integrados en la sociedad de los opresores. La trama comienza cuando un ejecutivo mestizo es advertido por su abuelo sobre un mal que se cierne desde el oeste: el renacimiento del espectro de una bruja nativa deseosa de extinguir el linaje de 
Águila Antigua -el anciano-y su nieto Mike. Al comienzo de la historia el joven comienza a padecer visiones de la talla de un tótem que más tarde se revelarán como el rostro mismo del espectro. Por otra parte, y de manera análoga a The werewolf, se fomenta la clave ecologista al dotar al fantasma de la capacidad de convertirse en animales o de manipularlos. En este sentido habría de encuadrarse la lucha entre Mike, parte del engranaje del sistema capitalista, y un oso grizzlie aparentemente dominado por la bruja, animal esencial en el proceso iniciático de entrada a la madurez en tribus indias como los navajo y símbolo de equilibrio y feracidad de la madre tierra. Naturalmente, el indio ofuscado por sus mismos ancestros vendría a representar los traumas de una cultura condenada a diluirse en la enormidad global de la sociedad estadounidense actual.

La identificación entre indios y espíritus guardianes de algún territorio sagrado vuelve a ser tópico en La sombra de Chikara (The shadow of Chikara, 1977), western donde el elemento fantástico aparece en medio de una narración aparentemente realista, como sucede en Abierto hasta el amanecer (From dusk till down, 1995). Para la ocasión, un grupo de desertores del ejército confederado emprende un viaje hacia una mina de Arkansas donde supuestamente abundan los diamantes. Por el camino se tropiezan con una superviviente de una masacre cometida por indios, interpretada por la que fuera pareja de Clint Eastwood, Sondra Locke. Una vez llegan al corazón de la montaña, inexplicables acontecimientos tienen lugar, como el hostigamiento de un águila que se ceba con la expedición, o espeluznantes ecos semejantes a lamentos arrastrados por el viento. Finalmente, la mujer resultó ser una especie de entidad espiritual defensora de la tierra, otra vez con poder sobre los animales y que se deshace de los soldados engatusándolos por medio de su belleza. La película cuenta con una estética propia de la época, muy condicionada por la atmósfera decadente explotada por Sam Peckinpah en Grupo Salvaje (The wild bunch, 1969) o La balada de Cable Hogue (The Ballad of Cable Hogue, 1970), además de plantear nuevamente los peligros inherentes a violar un territorio místico para los indios (Río, 2005, p. 113).

Paradójicamente, el primer film con un presupuesto más allá de la serie B sería también el de argumento más disparatado hasta la fecha. Dirigida por el malogrado William Girdler, Manito (The manitou, 1978) nos cuenta la historia de Karen -Susan Strasberg-, una mujer a quien diagnostican un tumor en el cuello que, en realidad, se trata de la reencarnación de un chamán cuyo plan es vengarse de la raza blanca. De puro hilarante, el guion no puede ser más superficial y evidente en la crítica que proyecta: la sociedad americana creció enferma, y con quistes tan prominentes como el indio vengador que crecía en la garganta de nuestra protagonista. El propósito sería extirpar esos traumas para seguir adelante.

A finales de década llegaría Terror en Amityville (The Amityville Horror, 1979), primera parte de una larga saga de películas basadas en hechos "reales". En ella, la típica familia media americana se traslada a una vivienda infectada por un mal que posee a sus habitantes y los obliga a cometer actos terribles. En 2005 se rodó un remake mucho más explícito, dirigido por Andrew Douglas, donde se concretan los orígenes de la maldición de la casa. El dato más llamativo para 
nuestro estudio sería la existencia de Jeremiah Ketcham, reverendo practicante de brujería y cuyo pasatiempo preferido era torturar indios en el mismo lugar donde se situaba el desván de la mansión. Es cierto que en esta película la figura del nativo no se utiliza como elemento vengador, pero sirve igualmente para rotular el cruel exterminio indígena por medio del terror cinematográfico.

\section{El "resplandor" del subgénero}

Si bien las producciones que hemos repasado hasta ahora son de una calidad al menos cuestionable, con el cambio de década llegaría una de las mejores películas no solo del "subgénero" de fantasmas indios, sino directamente del terror universalmente entendido. El resplandor (The Shinning, 1980) es simplemente otra muestra de la sublimación fílmica alcanzada por el neoyorquino Stanley Kubrick, capaz de abordar con éxito cualquier género cinematográfico que se proponga, en lo que es una gesta al alcance de poquísimos cineastas (Pérez, 2011, p. 2).

Tras la fría recepción por parte del público de la excepcional Barry Lyndon (1975) y después de haber rechazado años antes la dirección de El Exorcista, Kubrick se propuso apostar por la adaptación de uno de los primeros best sellers del también afamado Stephen King. Con el tiempo, la obra se convirtió en una película de culto en gran medida por la mítica actuación de Jack Nicholson, así como por las mejoras introducidas en una historia mucho más profunda de lo que nunca llegó a ser la novela. El director haría valer algunos de los aspectos necesariamente intrínsecos al cine, como la fotografía, en gran medida regida por un carácter simétrico, los magníficos planos secuencia apoyados en la, por entonces novedosa, steadicam -recordemos la célebre escena del triciclo y las niñas al final del pasillo-y una atmósfera histriónica y desasosegante amparada en el contraste de colores fríos y cálidos (Calabrese, 2012, p. 66).

No por archiconocida dejaremos de comentar, aunque sea brevemente, la historia de Jack Torrance, personaje en cierto modo patético, pues estamos ante un profesor que no enseña, un escritor incapaz de escribir $y$, más grave aún, un padre de familia de implicación cuestionable. Bajo estos condicionantes, a Jack se le ofrece ser guarda de invierno del Overlook, hotel que en los meses de frío queda aislado por las nieves y que debe ser mantenido para evitar daños en la red eléctrica y de fontanería. A pesar de los cinco meses de encierro, junto al hecho de que su antecesor en el cargo enajenara y aniquilase a su familia, el protagonista acepta el trabajo. Por su parte, su hijo Danny, dotado de grandes poderes extrasensoriales -el resplandor- es reacio a acudir porque percibe el mal creciente de un edificio construido encima de un terreno maldito.

Todos los cambios respecto a la literatura de King 5 iban encaminados a conformar una obra menos explícita en su acabado, desechando algunos elementos que 
bien podrían considerarse vulgares $\mathrm{u}$ ordinarios ${ }^{6}$. Por tanto, el núcleo primordial de la narración avanzaría al tiempo que el protagonista va enloqueciendo, pero Kubrick juega al despiste explicando el hecho tanto por la diabólica influencia del hotel como por el ya de por sí inestable carácter de Torrance. También se prescindió de los "árboles animados" del libro para sustituirlos por el famoso laberinto, así como de la explosión final del hotel. Pero quizá la aportación de Kubrick más llamativa sea precisamente el subtexto dedicado al holocausto indígena ${ }^{7}$, algo que se puede percibir si se tiene la paciencia para analizar los pequeños rastros dejados por un director detallista y que nunca, ya sea por el color, la colocación de los objetos o la música, deja lugar a la arbitrariedad.

En una de las primeras escenas del film se afirma que el hotel comenzó a edificarse en 1907 sobre un cementerio indio, por lo que varias tribus indígenas de la zona intentaron boicotear la construcción con el fin de conservar su terreno sagrado. Imaginemos por un momento la angustia de los nativos en ese difícil contexto, consumidos por sentimientos de ira y resabio hacia la raza blanca que acabarían por contaminar de energías negativas la zona donde se construiría el hotel, por no hablar de la multitud de difuntos execrados.

Si nos damos cuenta, Kubrick juega irónicamente a lo largo del metraje con esta confrontación entre nativos y colonos; paradigma de ello son las latas de conservas calumet -pipa de la paz- aparecidas en el refrigerador, recordatorios vacuos de una amistad que nunca llegó a existir; también son obvios los motivos indígenas colocados en la pared del gran salón donde Torrance escribe su "novela" al tiempo que caía en la locura; no olvidemos tampoco los cuadros de jefes indios que adornan el hotel por doquier, trofeos morbosos de personalidades asesinadas $o$ condenadas a vivir en reservas, y finalmente las figuras indias de motivos geométricos apreciadas en las moquetas, que parecían guiar al pequeño Danny hacia la prohibida habitación 237 . Todo ello se entremezcla con símbolos propiamente yankees como el águila -mostrada en el despacho durante entrevista y también en la camiseta de Jack-, nada menos que el emblema del sello americano y las trece colonias, pero en su origen ídolo totémico nativo, o el hecho de que la fecha de la fotografía del plano final sea el 4 de julio, efeméride de autoafirmación de la nación americana que es igual a decir desafirmación de los pueblos autóctonos.

Bajo la producción de Steven Spielberg y la dirección de Tobe Hooper-El misterio de Salem's Lot-vería la luz dos años después otro de los hitos del terror contemporáneo, Poltergeist: fenómenos extraños (Poltergeist, 1982). Referencia ineludible en el subgénero casas encantadas, existe una creencia errónea sobre la naturaleza del mal que da origen al poltergeist, pues en varias páginas webs y blogs especializados se sostiene que la casa donde ocurren los fenómenos se construyó encima de un cementerio indio. Sin embargo, en la película no se dan evidencias al respecto (López, 2007,p. 105), y más bien aparecen suficientes indicios para deshacer esta teoría: primeramente porque aparecen varios fantasmas bajando

6 http://filomusica.com/filo25/resplandor.html. Consultado (12/09/2016).

7 En la novela de Stephen King esto no aparecía. 
Imagen 2. Obsérvense los motivos indígenas como telón de fondo durante la inundación de sangre. Creemos que la metáfora no puede ser más elocuente.

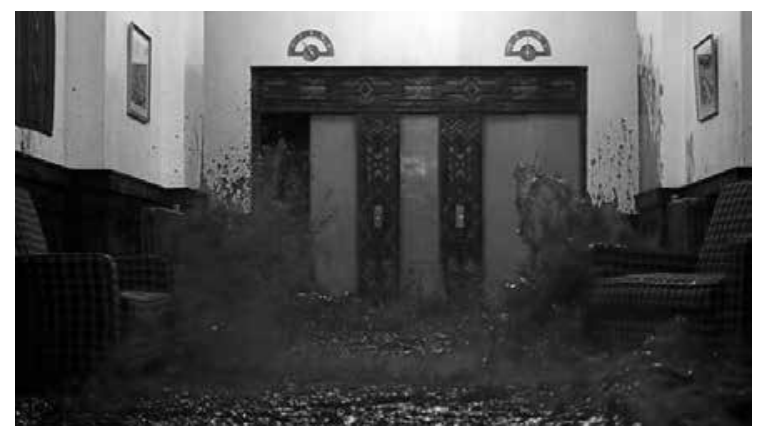

Fuente: Fotograma perteneciente a El resplandor.

por las escaleras ataviados con ropajes propios de finales del s. XIX y segundo, porque hacia el final de la narración, cuando los sucesos paranormales aparecen desbocados, emergen ataúdes desde el suelo de la casa descartando el origen indio de los fenómenos por el tipo de enterramiento occidental.

Ya en la segunda parte, Poltergeist II: el otro lado (Poltergeist II: the other side, 1986) descubrimos cómo el origen del mal se debía a una extraña secta cristiana inmolada en una gruta bajo tierra por orden de su líder religioso. Henry Kane, que así se llama el reverendo, hizo pactos con el mal y se valió de las almas de sus seguidores para ganar poder. Sin embargo, su energía no era infinita y de ahí que necesitara la presencia de la pequeña Carol Anne, entidad viva en el otro lado, y que bien podría servir de atracción para otros espíritus de los cuales Kane podría alimentarse. Con el objetivo de ayudar a derrotar a La Bestia, la familia Freelings obtiene en esta segunda parte la ayuda de un chamán indio que ejerció como enemigo del reverendo tiempo atrás. Esto, unido al hecho de que la acción se desarrolle en las llamadas Spider Rocks de Arizona, territorios tradicionalmente ocupados por los indígenas, evocaría una lucha entre el misticismo nativo, eminentemente animista y desprovisto de intereses materiales, y la religión cristiana, deformada en su representación por una secta extremista, pero cuyo fondo es similar al de otras creencias salvíficas occidentales: manipular a través del adoctrinamiento moral y la propagación del temor. Así pues, también estaríamos ante un revisionismo de la cultura precolonial, subrayándose las partes positivas de su modus vivendi en contraposición con nuestra forma actual de entender lo trascendente

El cine elevado de Kubrick y la eficiencia de Hooper ${ }^{8}$ dejarían paso nuevamente al bajo presupuesto de Scalps (Scalps, 1983), slasher donde unos jóvenes 
arqueólogos universitarios son masacrados por un espectro guardián del territorio. A diferencia de La sombra de Chikara, el fantasma posee a uno de los estudiantes y va aniquilando al resto en una narración simple y predecible. Como curiosidad, en la primera escena del film se hace visible el espíritu en forma de híbrido entre puma y humano, escudriñando desde la lejanía la llegada de los jóvenes. De nuevo, lo vemos, se establece un paralelismo entre los animales -el puma es un animal prácticamente extinto en EE. UU.- y los mismos indígenas.

Imagen 3. Espectro vengativo indígena de Scalps.

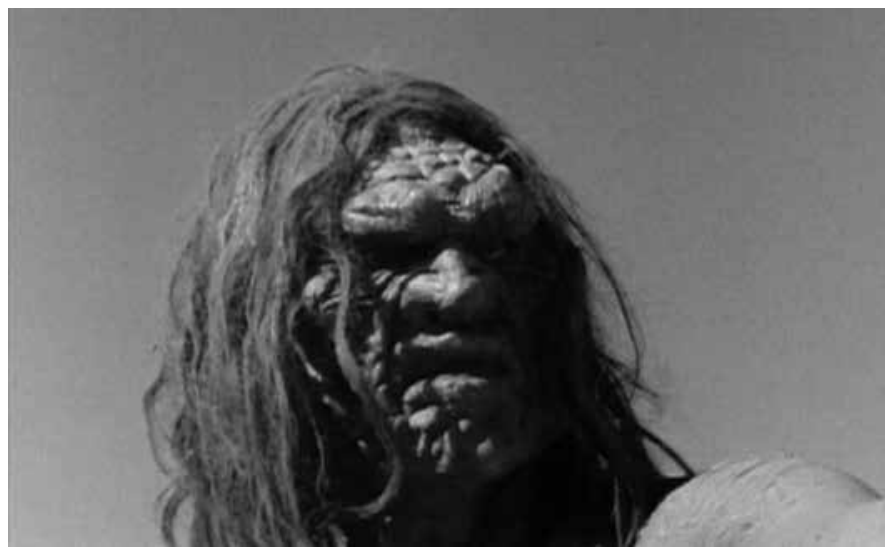

Imagen 4. El espíritu con forma de felino

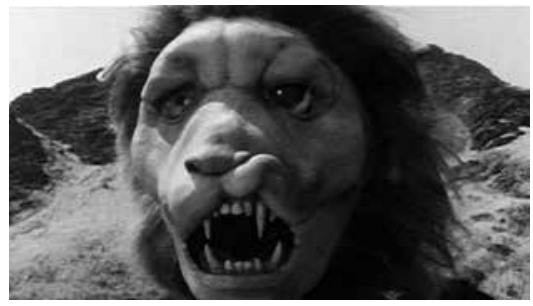

Fuente: Fotogramas pertenecientes a Scalps

La franquicia de historias cortas de terror Creepshow (Creepshow II: Dead and Undead, 1987) también contribuiría adaptando un relato breve de Stephen King llamado "El viejo jefe cabeza de madera". La acción nos sitúa en un pequeño pueblo del sur estadounidense, lugar donde una anciana pareja regenta una humilde tienda-almacén. Tras recibir una serie de joyas en fianza por las deudas que los indios del lugar arrastran con el tendero, tres jóvenes, entre los que se encuentra un piel roja, saquean el lugar, asesinan a la pareja y se llevan las reliquias. Después de la huida, la estatua de un guerrero indio colocada en la puerta del establecimiento cobra vida y caza a los tres delincuentes cortándole las caballeras. Durante el desarrollo de la historia se especifica que el malhechor indígena deseaba el dinero para huir a Hollywood y ser actor de cine, ensayo 
aberrante del sueño americano, siempre según bajo la primigenia moral autóctona. A castigar tanto el asesinato de los ancianos como esta degeneración imperdonable vendría un heraldo equilibrador, un guerrero de madera fruto de la creencia nativo-animista que otorga espíritu a casi cualquier objeto.

Imagen 5. Uno de los protagonistas siendo castigado por el "jefe cabeza de madera".

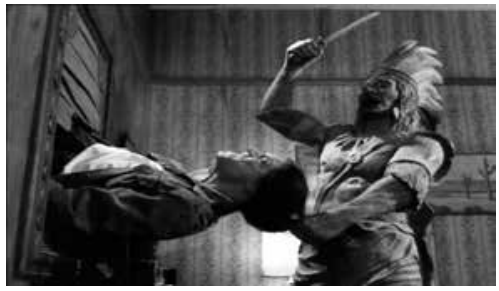

Fuente: Fotograma perteneciente a Creepshow 2.

Sin abandonar las adaptaciones de Stephen King, llegamos a Cementerio viviente (Pet Sematary, 1989), film con cameo incluido del propio escritor, con algún premio razzie en su haber, y que, como la novela, intentaba rescatar de manera libre ciertos mitos nativos. Aquí, otra típica familia americana se muda a una casa cerca de un cementerio de animales particularmente especial: todo ser fallecido que se entierre en ese terreno resucitará, pero como una sombra grotesca de lo que llegó a ser en vida. Finalmente, el círculo de rocas resultó ser un lugar de culto indígena al wendigo, criatura del folclore amerindio a medio camino entre la naturaleza espiritual y la física. No por reiterativo podemos dejar de destacar la relación entre los indígenas y los animales, que en la película se muestran como víctimas -ahí está el gato Church- de los recurrentes atropellos cometidos por camiones que transitaban por la carretera del pueblo. Visto lo visto, ¿sería esto un grosero intento de evocación del ferrocarril y la reclusión de tribus en reservas? ${ }^{9}$

Quizá uno de los espíritus vengativos indios más famosos en los medios audiovisuales sea el del asesino Bob de Twin Peaks (Twin Peaks, 1990), serie creada por el controvertido David Lynch sin la que no podríamos entender el refinamiento estético y narratológico alcanzado por hitos actuales como True Detective (True Detective, 2014). De éxito sin precedentes para la televisión de la época, el hilo argumental comienza con la muerte de una a priori ejemplar adolescente-Laura Palmer- en un pueblo del Estado de Washington, colindante con la frontera de Canadá. A resolver el asesinato llegaría un excéntrico agente del F-B-I llamado Dale Cooper, interpretado por el en aquel momento pujante Kyle MacLachlan. Como si de un rito iniciático se tratara, el policía va percibiendo cómo la normalidad de la comunidad que investiga es simplemente una façade con asuntos mucho más turbios detrás (Smith, 1993, p. 258). En Twin Peaks la misma atmósfera evoca un lugar de encrucijada donde lo cotidiano, lo onírico y lo esotérico

9 A pesar de lo burdo de la comparación, en ambos casos se antepone el interés por el desarrollo y la economía capitalista a la vida y seguridad de indios y animales respectivamente. 
conviven diariamente, aunque a costa de una población condicionada por la presencia del mal intangible, a la sazón origen de los sórdidos acontecimientos desarrollados en escena.

Es el momento de sacar a colación las constantes alusiones a la imaginería indígena en el hotel donde se aloja Cooper, o incluso la presencia de indios integrados en la colectividad de Twin Peaks, como el policía Hawk -águila, en inglés-. Todo ello nos habla de una localización previamente habitada por nativos que, a juzgar por los acontecimientos, fueron desplazados. Poco después nos cercioramos de que aquella sociedad rural convivía junto a un bosque maldito ${ }^{10}$-quizá por los indios que fallecieron en ese mismo lugar- lo cual generó una circunstancia que no habría de ser problemática si se aplicaban ciertas reglas ${ }^{11}$. No obstante, el fantasma de un indígena asesino y violador llamado Bob se filtra desde el bosque hacia Twin Peaks, terminando por ocasionar daños irreparables en forma de posesiones espectrales y diversas muertes ${ }^{12}$.

Imagen 6. La influencia de Bob como mal absoluto en muchos de los personajes del pueblo es constante

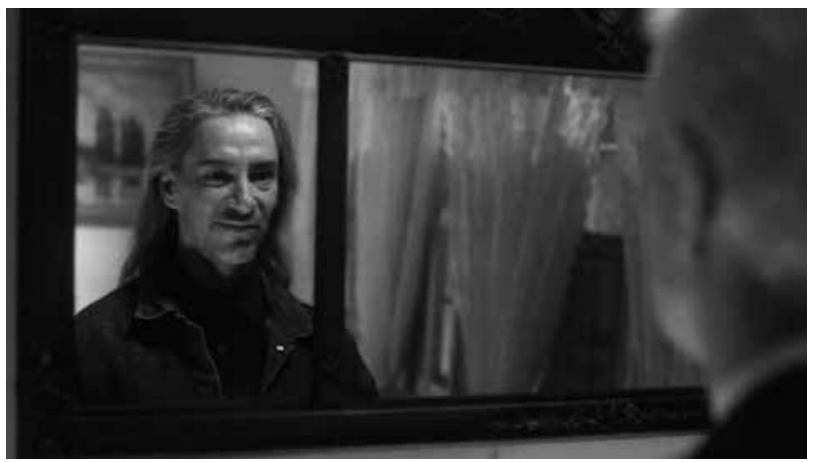

Fuente: Fotograma perteneciente a Twin Peaks.

Para la historia de la televisión quedará la escena donde el espíritu de Bob, agazapado y a los pies del sofá, mira fijamente a la desequilibrada madre de Laura Palmer durante el episodio piloto.

La década de los 90 se inauguraría con la peculiar película de episodios Los cuentos de Grim Prairie (Grim Prairie Tales: Hit the Trail... to Terror, 1990). De exiguo presupuesto, el film destaca por presentar entre el reparto a James Earl Jones, quien en su momento pusiera voz a Darth Vader y rostro a Thulsa Doom villano en Conan el Bárbaro - ; así como a Brad Dourif, lengua de serpiente en la adaptación de $E l$ señor de los anillos para la gran pantalla. Sumergiéndonos en

10 http://www.twinpeaks.org/faqeps.htm. Consultado el 20/01/2017.

11 Por ello la organización de la Logia Blanca.

12 La más sonada de todas sería la de Laura Palmer a manos de su padre Leland, poseído por Bob. 
la narrativa, los personajes interpretados por ambos actores deciden relatarse mutuamente historias de terror a la luz de la hoguera mientras pernoctaban en pleno desierto. El primer relato versa sobre un cowboy que en su tránsito por una necrópolis indígena mascullaba mofándose de los muertos. De pronto, reparó en un cuerpo aún fresco sin poder evitar acercarse y contemplarlo, gesto fatal que le procuró tanto una mordida en el cuello como acabar enterrado para siempre en ese camposanto. La cuarta historia presenta un duelo a pistola entre un vaquero blanco y un indio asimilado en el que acaba imponiéndose el primero. Al día siguiente, mientras el ganador se afeitaba frente al espejo, el espectro del indio lo poseyó haciendo que se cortase la yugular.

Cerraremos el epígrafe con El guardián de los muertos (Uninvited, 1993), otra cinta menor en la que un heterogéneo grupo adquiere terrenos donde supuestamente existen enormes cantidades de oro. Cuando la improvisada compañía entiende que el enclave se trata de un cementerio indígena, comienzan a padecer pesadillas que actúan como prolepsis de lo que aún estaba por llegar. Pronto, un indio se dirigiría hacia ellos instándoles a abandonar las tierras, pero los protagonistas le responden ahorcándolo sin vacilación alguna en un árbol. Como el lector podrá suponer, el nativo era en realidad el espíritu protector de aquel dominio sagrado, por lo que comenzaría a ofuscar desde entonces la mente de sus agresores, sembrando entre ellos el terror, la envidia y el odio. Si bien en esta ocasión el desenlace se explica en función de una intervención sobrenatural, no podemos dejar de evocar el final de dos películas ilustres del maestro John Huston: El tesoro de Sierra Madre (The Treasure of the Sierra Madre, 1948) y El hombre que pudo reinar (The Man Who Would Be King, 1975).

Por reiteración, el esquema anterior nos resultará a estas alturas muy familiar, reafirmando a su vez la vanidad y materialismo exacerbado de la raza blanca, capaz de mutilar la naturaleza o cualquier rasgo de alteridad con tal de conseguir sus vacuos objetivos. Aquí recordaremos un episodio de otro western como contrapunto, Las aventuras de Jeremiah Johnson (Jeremiah Johnson, 1972), en el que el protagonista interpretado por Robert Redford se mostró renuente a

Imagen 7. En la imagen observamos el cementerio indio que el protagonista se ve obligado a cruzar a su pesar.

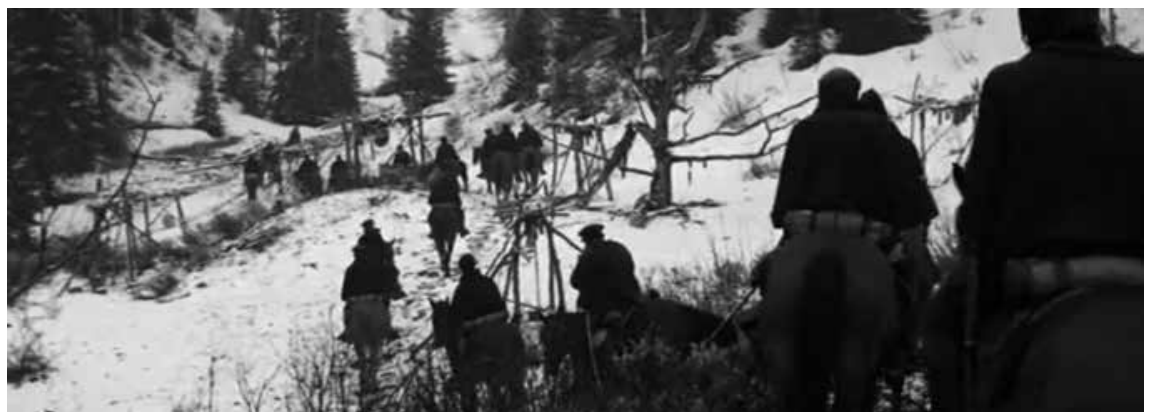

Fuente: Fotograma perteneciente a Las aventuras de Jeremiah Johnson. 
atravesar un cementerio indio granjeándose la incomprensión de los soldados nordistas. Solo alguien como él, que vivió respetando las reglas impuestas por la naturaleza y los elementos, podía ser sensible a las creencias de otros, por mucho que pertenecieran a una raza distinta.

\section{Folk indígena en el terror del siglo XXI}

Quizá sea el efecto psicológico resultante de dar el salto a un nuevo siglo; tal vez el hecho de dirigirse hacia una nueva etapa donde Internet, las redes sociales y la preeminencia de lo global respecto a lo particular cobren cada vez más valor, pero lo cierto es que el terror y el fantástico referentes al universo nativo americano estarán condicionados no solo por espíritus de chamanes, cementerios o fantasmas, sino también por algunas criaturas del bestiario precolonial que a partir de ahora cobrarán un especial protagonismo. Pareciera como si todo aquel conjunto de creencias quisiera alzar la voz y utilizar el cine para gritar que existen. Al fin y al cabo, lo anterior quizá sirva para saldar deudas con aquella sociedad que los ha condenado al ostracismo y a una inexorable desaparición.

Esto ya empezó a percibirse en el capítulo diecinueve de la primera temporada de Expediente X (The X-Files, 1993) llamado "shapes"13, donde Mulder y Scully viajan a una reserva india para resolver la muerte de un nativo confundido con un animal salvaje. Todo empieza a complicarse cuando salieron a la luz las disputas que Jim Parker mantenía con el muerto por desavenencias en el linde de sus territorios. Además, el estudio forense cuestiona la posibilidad de que Parker confundiera a la víctima con una bestia debido a la cercanía del disparo. Poco después, los investigadores consideran la posibilidad de explicar lo ocurrido a través del mito del cambiaformas, una legendaria capacidad de algunos indios para adoptar la figura de un lobo gigante o un oso. Finalmente, el "presunto" asesino de raza blanca fue hallado descuartizado por lo que parecía ser una criatura salvaje de enormes proporciones. Es muy interesante resaltar cómo en este pequeño episodio se hallan condensados perfectamente los clichés del género, a saber: disputa entre un blanco y un indígena por el mismo espacio territorial, a pequeña escala lo mismo que ocurrió con la conquista del Far West; connotación ecológica al asimilar la muerte del nativo con la desaparición del yo animalístico, metáfora elocuente de pertenencia a la tierra como concepto matriz y de empatía hacia otros seres vivos, y por último, venganza acometida por parte de otro indio debido a los agravios hacia su raza.

El wendigo (Justus, 2014, p. 1), concepto que guarda algunos paralelismos con lo anterior, sería el tema principal de la infravalorada Ravenous (1999), obra denostada por crítica y público, pero a nuestro juicio muy valorable si atendemos a la calidad de su atmosfera pesadillesca, así como a su inteligente fluctuación entre realidad y fantasía. También basado en hechos reales, el argumento comienza 
cuando un trampero escocés llega a un puesto fronterizo de montaña vigilado por una pequeña guarnición del ejército. Delirante y en unas condiciones lamentables, narra cómo quedó atrapado junto a su expedición por la nieve y la manera en que sobrevivió alimentándose de sus propios muertos. Sin embargo, la realidad era mucho más perversa, pues el trampero Colqhoun aniquiló a sus compañeros al caer poseído -supuestamente- por el wendigo, lo cual le acabaría por despertar devoción hacia la carne humana. La película está construida de tal forma que el espectador es libre de creer, en efecto, en la posesión del hombre por el espíritu, o bien directamente en la enajenación de Colqhoun ante una coyuntura extrema. De cualquier forma, ahí está el mito nativo como eje de la acción, ya sea conjurando mediante el inconsciente del individuo la culpa por matar indios y esquilmar la tierra, o directamente actuando como elemento castigador.

El mito cambia de forma radical en Escalofrío (Wendigo, 2001), ya que aquí se opta por dejar a un lado las ambigüedades y abrazar sin ambages la explicitud de monstruo convencional. En este caso, el ser persigue vehementemente a una familia que atropella por accidente a un ciervo y a los hombres que iban a cazarlo. Como curiosidad, el wendigo es presentado con la forma de un gran venado bípedo, prescindiendo de la asimilación con el lobo tradicionalmente aceptada. En suma, a pesar de ser una producción horrible en su acabado, nos sirve para corroborar el profundo sentido naturalista inmanente a la leyenda.

Siete años después, el mismo director, Larry Fessenden, dirigiría un episodio de la serie Terror en estado puro (Fear Itself, 2008) llamado "Estar en los huesos" ("Skin and bones", 2008) en el cual se retomaba la leyenda del wendigo, aunque desde un prisma mucho más cercano a la ya comentada Ravenous. En la historia, un hombre vuelve a su casa aparentemente al límite de sus fuerzas tras estar incomunicado más de una semana en la montaña. A primera vista, su extraño comportamiento se explicaría en función de la desnutrición, pero como el lector podrá llegar a suponerse, en realidad el personaje cayó poseído.

La serie de género Masters of Horrors (Masters of Horror Series, 2005) también hizo su particular homenaje al bestiario amerindio por medio de Salvaje instinto animal (Deer Woman, 2005) un divertidísimo mediometraje dirigido por John Landis -Un hombre lobo americano en Paris- que nos presentaba una serie de asesinatos con dos únicos nexos de unión: las víctimas aparecían destrozadas por los cascos de un ciervo y coincidían en haber sido vistas por última vez en compañía de una bellísima mujer india. Aparte del tono caustico propio del director chicagoense, aquí se prescinde del ecologismo para convertir a la mujer ciervo en una female avenger muy en la línea del fantasma japonés de posguerra.

Para finalizar este repaso nombraremos un pastiche llamado The Sacred (2009) con claras referencias visuales a Sam Reimi en Posesión Infernal (The evil dead, 1981) y a Wes Craven en Scream (1996). Su desarrollo parece cumplir cliché tras cliché los hitos fundamentales del género, puesto que por enésima ocasión los blancos se adentran en una zona repleta de fantasmas indígenas repletos de resentimiento. 
Imagen 8. Durante esta escena la mujer ciervo es atropellada por un coche, en una figuración evidente de lo que ocurrió con los indios y su mundo de las mentalidades con el advenimiento europeo.

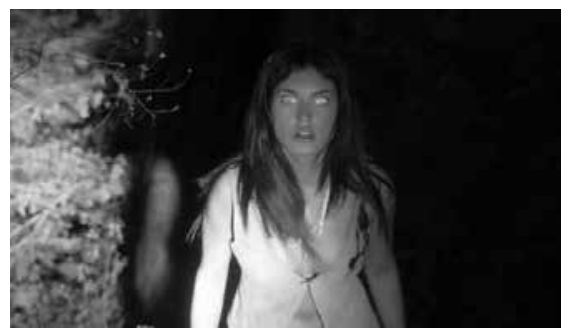

Fuente: Fotograma perteneciente a Salvaje instinto animal.

\section{Negros, gitanos y judíos}

Respecto al cine de terror y fantasía cuyos protagonistas son afroamericanos, debemos diferenciar las películas paródicas fruto del movimiento blaxplotaition ${ }^{14}$ en los 70 - como Dr. Black y Mr. Hyde o Blackula- de los films verdaderamente vindicadores de una situación social deprimida (Howard, 2008, p. 12). Nos es imposible hacer un repaso concienzudo por estas producciones, pero sí nombraremos algunas de las más importantes para constatar el fenómeno.

Entre ellas es de obligada mención Candyman, el dominio de la mente (Candyman, 1992) film inspirado en un relato del maestro Clive Barker, a su vez padre de una de las obras más subversivas del horror de los 80 (Márquez, 2007, p. 77) como fue Hellraiser (1987). Candyman trata sobre una doctoranda de antropología que estudia el impacto de una leyenda urbana surgida en los suburbios de Chicago. Según los negros del gueto, un fantasma al que preceden miles de abejas, ataviado con gabardina y con un garfio en vez de mano, se aparece ante quien pronuncie su nombre tres veces delante de un espejo. Indagando sobre el origen del mito, un profesor de la universidad explica a la estudiante-Virginia Madsen- su base histórica y la serie de "supersticiones" que han podido darle forma. Supuestamente, Candyman es el espíritu de un esclavo mutilado y asesinado por sus amos en castigo a una violación que nunca cometió. La forma de acabar con él consistió en cubrirlo de miel para que una multitud de abejas lo atacase, procurándole una lenta y dolorosa muerte. La actitud escéptica e incluso soberbia de la investigadora ante la ignorancia de la gente de los suburbios pronto se convertirá en una prueba para su mente racional, que ve cómo diversos asesinatos realizados por alguien con garfio comienzan a sucederse a la vez que avanza en la investigación.

14 Movimiento cinematográfico de los 70 cuyo eje fue un cine íntegramente hecho por y para afroamericanos. Las producciones se caracterizaban por un gran protagonismo de la música funk y la parodia de películas preexistentes. 
Es obvio que tanto en la película como en el relato se enfatiza el papel humillante desempeñado por los negros en la historia de América. Su situación de esclavitud, o bien su naturaleza jurídica prehumana, servían de motivación para tratos vejatorios a finales del siglo XIX tan extremos como el ya narrado. No obstante, un siglo después seguía existiendo otro tipo de represión más sutil, aquella cerniente sobre ciudadanos presuntamente libres, pero en efecto en los límites de lo cívicamente aceptado, mirados siempre con recelo y en la cola del escalafón social. Es muy sugerente pensar cómo ese complejo de inferioridad racial es capaz de originar una leyenda urbana a medio camino entre el deseo de desagravio de unos y el sentido de culpa de los otros -al fin y al cabo, se recuerda el hecho traumático a modo de catarsis mirándose frente a un espejo-. Si el fantasma es real o no, a nosotros no nos importa demasiado, aunque el título del film en ciertos países se esfuerce tanto por despejar las dudas. Mucho más importante es la existencia de la leyenda urbana en sí misma, mecanismo equilibrador y ajusticiador, si se quiere, de una comunidad con distintas varas de medir según la raza.

Imagen 9. La potencia visual de Candyman nos resulta más que evidente.

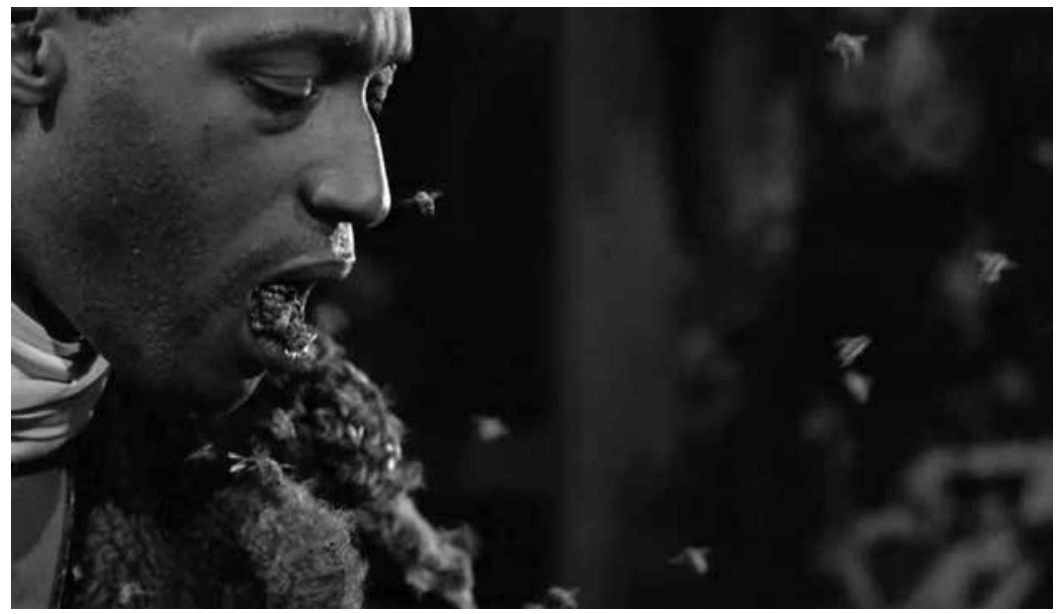

Fuente: Fotograma perteneciente a Candyman, el dominio de la mente.

Beloved, novela ganadora en 1988 del premio Pulitzer, fue adaptada por el director Jonathan Demme-El Silencio de los corderos-mediante un film tachado de irregular por la crítica especializada: Beloved, (1998). Su historia gira en torno a otra esclava llamada Sethe-Oprah Winfrey-que decide acabar con su hija recién nacida con el fin de evitarle el sufrimiento de crecer bajo el yugo de la esclavitud. Tras la Guerra de Secesión, cuando la protagonista reencauza su vida junto a un hombre llamado Paul D., recibe la visita de una joven con indicios de ser el fantasma de su hija muerta. Al principio del film el espíritu tan solo habita, incorpóreo, en la casa de su familia, y, a pesar de manifestarse asiduamente -la película se abre con un violento poltergeist-, es aceptada como una parte más de 
las vidas de los habitantes de la cabaña. Sin embargo, con la llegada del hombre-Danny Glover- se remueven los recuerdos de los años en la plantación de Sweet Home y el fantasma deja de actuar para presentarse con la apariencia de una jovencita con la edad que hubiera tenido la hija de Sethe de haber seguido viviendo. Metafóricamente con Paul llegó la catarsis y la oportunidad de ser definitivamente felices, pero en ese enfrentamiento contra lo reprimido, contra los terrores sufridos en los años de esclavitud, los protagonistas de la historia pierden irremediablemente. Así, Beloved es en efecto el fantasma de la hija de Sethe, aunque también lo es de toda aquella amalgama de sucesos traumáticos imposibles de olvidar, y que acaban retornando para atormentar a los vivos.

En palabras de Marina Fe, "la memoria misma es un fantasma que persigue y acosa de noche a los personajes de esta novela, que se posesiona de sus cuerpos y sus mentes como antes fueron poseídos por sus amos blancos..." (Fe, 2008, p. 125).

Si mezclamos ciertos elementos del relato de Toni Morrison con la textura visual propia del terror gótico obtendremos Los inocentes (2015), reciente hallazgo ejemplificador de las penurias sufridas por los negros en la Argentina de mediados del siglo XIX. La acción dramática se desarrolla en una próspera pero espeluznante finca llamada La Mercedaria, cuyo patrón, cruel y bestial, solo vive para infligir suplicios a sus esclavos. Especial fijación sentía hacia una bellísima esclava negra a quien violaba sistemáticamente, y que, a la postre, sería quemada viva a instancias de la esposa del hacendado. La cinta, de aspecto absolutamente realista e inclinada en su primera mitad al drama histórico, va adquiriendo poco a poco tintes sobrenaturales hasta verse desbocada en su desenlace, cuando la familia Arguelles cae devastada bajo la influencia del espectro de aquella esclava ultrajada.

Cambiando de tercio, el gitano ha actuado en el cine y literatura de terror frecuentemente como una figura negativa o de mal agüero, algo obvio si nos atenemos a su concepto social en la enorme mayoría de culturas europeas. Ahí tenemos a los servidores de Drácula, gitanos dispuestos a dar la vida por satisfacer a su amo (Stoker, 2002, p. 490), o a Maleva, bruja que popularmente desvela el estigma del hombre lobo a su portador en las diferentes versiones cinematográficas del mito. Pero si existe una actividad característica del gitano en los relatos fantásticos esa, sin duda, es la de maldecir.

Así ocurre en Thinner (1996) otra adaptación de Stephen King dirigida por el inconstante Tom Holland (Fright Night). En ella, un exitoso y obeso abogado atropella a la hija de un patriarca gitano mientras su esposa le practicaba sexo oral en el coche. Se inicia de este modo un juicio en el que el protagonista, en connivencia con el juez y las autoridades, trastoca los hechos omitiendo la causa de su descuido al volante para ser declarado inocente. Al día siguiente el jefe del clan gitano -Michael Constantine- increpa al abogado y lo maldice pronunciando la palabra thinner ${ }^{15}$, punto de partida para un descenso a los infiernos 
por parte de nuestro protagonista que, a partir de ahora, no haría más que adelgazar antinaturalmente. Aquí es muy interesante destacar la enorme crítica realizada hacia la sociedad burguesa, siempre en disposición de censurar otras etnias y culturas desde su situación de preeminencia, pero bocetada como un engendro donde la plétora, la depravación y la corrupción no conocen límites.

De temática similar es el trabajo de Sam Raimi Arrástrame al infierno (Drag me to Hell, 2009) cuya trama gira en torno a Christine Brown -Alison Lohman-, joven emprendedora y ansiosa por ascender en el escalafón de la entidad bancaria donde trabaja. Para ello, intenta impresionar a su jefe negando una prórroga en la hipoteca a la gitana Ganush, que en represalia maldice a la protagonista después de una porfía dentro de unos aparcamientos subterráneos. El embrujo se caracterizaba por ser particularmente perjudicial, pues durante los siguientes tres días un demonio procuraría a la maldecida toda serie de tormentos antes de "arrastrarla al infierno" definitivamente.

Imagen 10. Ganush, la bruja gitana de Arrastrame al infierno.

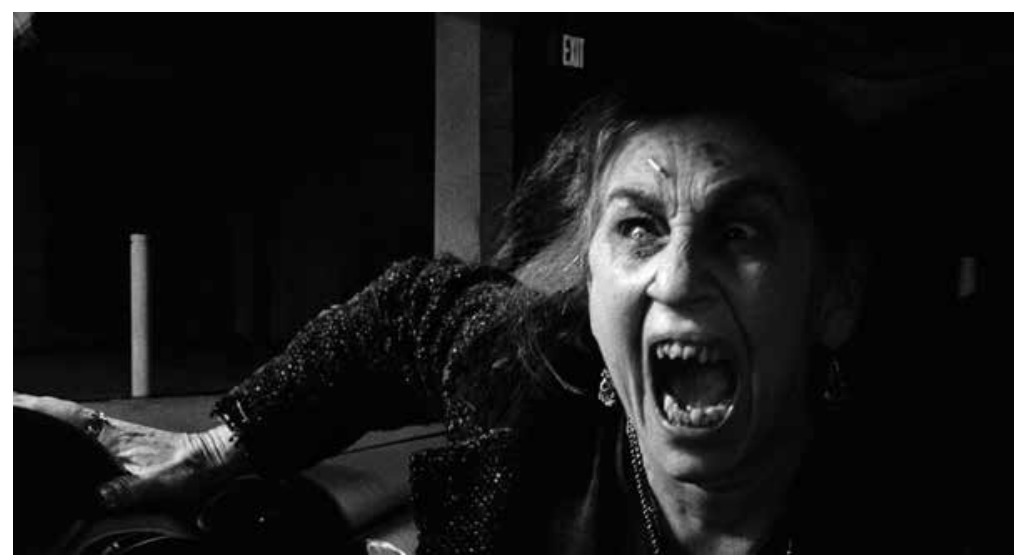

Fuente: fotograma perteneciente a Arrástrame al infierno.

En cuanto a las reivindicaciones sobrenaturales perpetradas por la minoría hebraica, destaca sobremanera El Golem (Der Golem, 1920) ${ }^{16}$ joya en ocasiones olvidada del expresionismo alemán, e inclusive anterior a Nosferatu, Metrópolis (1927) o Vampyr, la bruja vampiro (Vampyr-Der Traum des Allan Grey, 1932); he aquí tan solo una muestra para entender su importante papel durante los primeros pasos del terror cinematográfico. La acción se desarrolla en los prolegómenos de la expulsión de la comunidad judía en Praga promulgada por el emperador Rodolfo II. Para evitar tal medida, el rabino Löw, alquimista, hechicero y maestro de la cábala, solícita la ayuda a diversos espíritus para que animen a un monstruo de tierra llamado "Golem". Cuando la criatura se deshace de las 
autoridades de la ciudad ansía seguir existiendo más allá de su cometido y se convertirte en una amenaza para toda la sociedad. Puede apreciarse claramente cómo la película dirigida por Paul Wegener es otra revisión más del mito de Frankenstein, así como, probablemente, uno de los primeros largometrajes de corte fantástico de la historia del cine $^{17}$.

Imagen 11. Uno de los demonios invocados por el rabino para animar al Golem

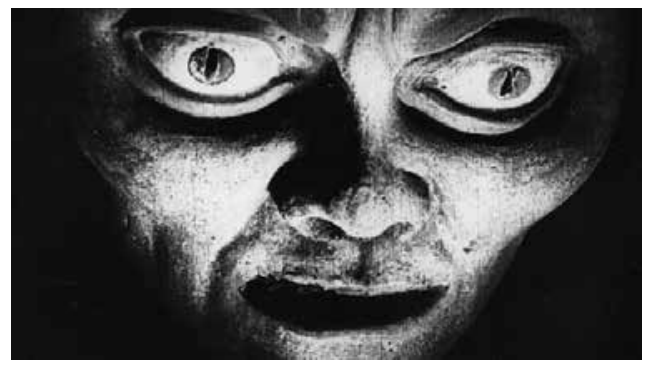

Fuente: fotograma perteneciente a El Golem.

Como curiosidad, Quentin Tarantino hizo un guiño al mito del Golem introduciéndolo en una conversación entre Hitler y un oficial nazi en su magnífica Malditos Bastardos (Inglourious Basterds, 2009) $)^{18}$.

\section{Conclusiones: un fenónemo pancultural}

Dijo Quinto Horacio que la pluma en mano de Clío es siempre guiada por la Victoria. En Japón, en EE. UU. o en la Praga moderna, los parias han sido condenados al silencio propio de los márgenes de sus sociedades, por lo que, consecuentemente, la historia oficial, junto a toda su producción artística, no es sino una escrupulosa selección de hechos realizada por los vencedores. Como hemos visto en nuestro estudio, el cine se ha usado como plataforma para que el conjunto de olvidados, de minorías y marginados, reivindique su negación y sus desventajas históricas, al tiempo que, febrilmente, fantasea recreando una pequeña venganza privada.

Venganza que lo es a título individual por deseo expreso del productor, del guionista o el director, pero que también representa un sentimiento ahogado de carácter plural, inconsciente o no, sufrido por algún sector secundario de la colectividad. Espíritus de indios y negros, criaturas pertenecientes a una cultura anterior de las que ya nadie se acuerda o maldiciones destinadas a compensar la balanza, son los mecanismos de unos perdedores lastrados por

18 A su vez una película que trataba sobre judíos vengadores.
} 
la voluntad de ser distintos, por ansiar mantener sus costumbres más allá del canon impuesto, y, claro está, también por razones socioeconómicas, morales y de índole estructural.

Es muy interesante resaltar cómo la enorme mayoría de estas producciones son humildes, de bajo presupuesto, como si sus alegaciones no pudieran - o debieran - ser escuchadas a gran escala. De ahí su carácter metafórico, pues recordemos que no es un indio o un esclavo quien habla quejándose directamente ante el espectador, sino que lo hace a través de su fantasma, eco de una sombra que actúa como elemento vertebrador de un género ya de por sí subsidiario y tenido poco en cuenta por las corrientes intelectuales del gran público. De este modo, todo es menos doloroso y trascendente, tanto el mensaje vindicador, diluido al tamizarse tras el elemento fantástico, como la cantidad de espectadores potencialmente aludidos, ya que, recordémoslo, tan solo estamos ante historias escritas para no dormir.

Es decir, ante unos simples cuentos de fantasmas.

\section{Referencias}

Bosch, R. (1986). El genocidio de los indios americanos. Historia 16(126), 77-88.

Calabrese, O. (2012). “El resplandor" de Stanley Kubrick. Un sistema de colores y pasiones. Tópicos de seminario, 28, 60-68.

Fe, M. (2008). Los fantasmas de Beloved. Anuario de Letras Modernas, 14, 125-131.

Howard, J. (2008). Blaxplotaition. Nueva York: Fab Press.

Justus, A. (2014). The spirit of the north country: the wendigo. Supernatural Magazine, 67.

King, S. (2013). El resplandor. Barcelona: Debolsillo.

Leyra, P. (1998). Los indios son los fantasmas de América. Entrevista a Oliver Stone. Cambio 16(1366), 58-59.

Lopez De Vigo, A. (2007). Poltergeist. Interfilms, 221, 105-110.

Marquez, J. (2007). Clive Barker. Terror para el nuevo milenio. Cambio 16(1181), 76-77.

Míguez, A. (2016) El fantasma en el cine japonés de posguerra. De rasgo folclórico a icono feminista. Córdoba: Universidad de Córdoba. 
Pedraza Martínez, M. P. (1996). Las últimas ogresas: histéricas, vampiras y muñecas. En T. Sauret Guerrero (Coord.), Historia del Arte y mujeres. Málaga: Universidad de Málaga.

Pérez Rufi, J. P. (2011). Estereotipos y cine de género en Kubrick. Espéculo: Revista de Estudios Literarios, 46. Revista académica online.

Río Raigadas, D. (2005). Espacio e identidad de un "western" crepuscular. En R. Merino Álvarez, E. Pajares Infante, y J. M. Santa María López (Coords.), Trasvases culturales. Literatura, Cine y Traducción. Bilbao: Universidad del País Vasco.

Smith, S. (1993). The knowing spectator of Twin Peaks: culture, feminism, and family violence. Literature/Film quarterly, IV (21).

Stoker, B. (2002). Drácula. Barcelona: Planeta DeAgostini.

Téllez, J. (2007). La noche de Haloween de John Carpenter. En S. Sunsunegui (Edit.), Contracampo: ensayos sobre teoría e historia del cine. Mádrid: Cátedra. 